\title{
Visualization Research and Analysis of Turnover Intention
}

\author{
Hui Liu ${ }^{1, a}$,Yan Liu ${ }^{1, b^{*}}$ \\ ${ }^{1}$ International Business School Shaanxi Normal University Xi'an, Shaanxi
}

\begin{abstract}
Turnover intentions plays an important role in predicting employee turnover behavior. In order to accurately identify research hotspots and evolutionary trends in turnover intention, this study uses the literature on departure inclination in the Web of Science core collection as the research object and uses CiteSpace.5.5 for visual analysis. The research results show that the research topics of turnover intention can be summarized into three aspects: the factors affecting turnover intention, the consequences of turnover intention, and the research methods. Although some researches on turnover intention have achieved certain results, there are still some problems such as lack of cooperation among researchers, few personal influence factors, and few studies on how to reduce turnover intentions. Based on this, some suggestions for future research directions are proposed.
\end{abstract}

\section{Introduction}

In recent years, employee turnover has become a key topic of concern for researchers and managers, and employee turnover intention as an important predictor of turnover behavior has also aroused widespread concern among scholars. Employees with turnover intention will exhibit passive downtime, reduce work input and other behaviors that are not conducive to the organization and bring potential danger to the organization. In more than 20 years of research, the research results of turnover intention are abundant, but they are scattered, and there is still a lack of a summary of the research hotspots and trends of turnover intention. Therefore, this article uses Citespace.5.5 for visual analysis, and uses a combination of qualitative and quantitative methods to summarize. It intends to identify the current status, research hotspots and evolutionary trends of current turnover intentions, and provide reference and guidance for researchers in related fields in the future.

\section{Data sources and research methods}

This article uses the foreign language database Web of Science core journal collection as the data source. When collecting data, the annual range was set to 2000-2019, and the search was conducted on the theme of "turnover intention" and "turnover intentions", and 888 articles were obtained. On this basis, this study uses Citespace.5.5 to carry out bibliometric analysis on literatures related to turnover intentions, and analyzes knowledge maps such as geographical distribution, author analysis, keyword cooccurrence and clustering, and detection of burst terms to help scholars familiar with the current status of turnover intention, grasp the research hotspots, sort out the evolution of the subject of turnover intention research, and identify the direction of future research.

\section{Research analysis}

\subsection{Geographical distribution}

Analysis of the geographical distribution of studies on turnover intentions shows that, as shown in Table I, USA has the largest number of articles, with 243 articles and the centrality is 0.68 . Followed by China, with 177 articles published, South Korea ranked third with 93 articles. The rest of the top ten regions in the study of turnover intention are shown in Table I.

TABLE I. National statistics

\begin{tabular}{|c|c|c|c|}
\hline Num & Freq & Centrality & Author \\
\hline 1 & 243 & 0.68 & USA \\
\hline 2 & 177 & 0.09 & PEOPLES R CHINA \\
\hline 3 & 93 & 0.01 & SOUTH KOREA \\
\hline 4 & 65 & 0.02 & TAIWAN \\
\hline 5 & 56 & 0.13 & CANADA \\
\hline 6 & 52 & 0.23 & AUSTRALIA \\
\hline 7 & 35 & 0.3 & ENGLAND \\
\hline 8 & 34 & 0.2 & GERMANY \\
\hline 9 & 29 & 0.07 & TURKEY \\
\hline 10 & 25 & 0.02 & MALAYSIA \\
\hline
\end{tabular}

\section{2 author statistics and cooperation network}

Through the author statistics, it can analyze representative authors and core strengths in the field of turnover intention research. This article uses Citespace.5.5 to select authors 
with an occurrence frequency greater than 1 to generate a cooperative network knowledge graph (see Fig.1). In addition, the top ten authors selected for the number of articles published are listed in Table II. Combining Fig.1 and Table II, it can be concluded that $\mathrm{Kim} \mathrm{H}$ is the author with the largest number of posts regarding turnover intention, followed by Allen DG, Battistelli A, Lin CP, and Knudsen HK, Ducharme LJ, Roman PM with more than 5 posts. These are representative authors in the field of turnover intention research. In addition, as shown in Fig.1, the connection between the authors represents a cooperative relationship, and the author $\mathrm{Kim} \mathrm{H}$, who publishes the most articles, is not in any network, indicating that he often publishes articles independently. It can be seen from Fig. 1 that there are a large number of smaller research circles in the network but a large cooperative network, indicating that scholars in the field of turnover intention are scattered and there is a lack of core authors who can act as a "bridge".

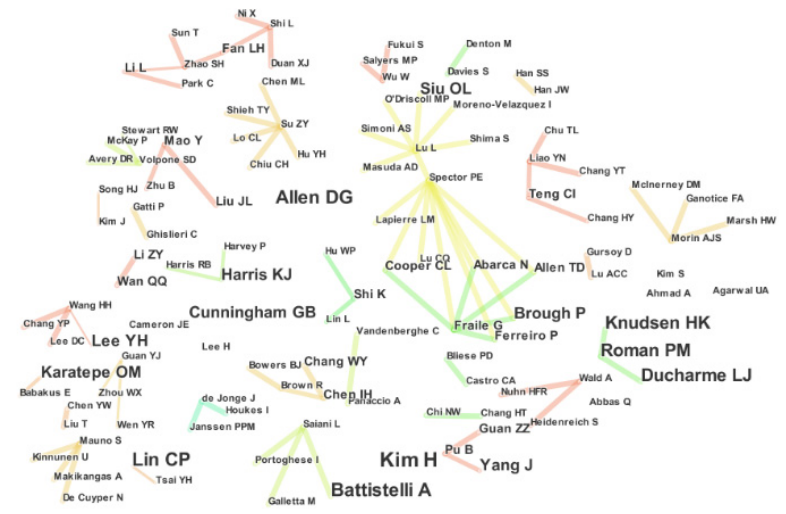

Figure 1. Turnover intention author collaboration network map

TABLE II. Statistics on the number of the first ten authors

\begin{tabular}{|c|l|c|c|c|c|}
\hline Num & Author & Freq & Num & Author & Freq \\
\hline 1 & Kim H & 7 & 6 & Ducharme LJ & 5 \\
\hline 2 & Allen DG & 6 & 7 & Roman PM & 5 \\
\hline 3 & Battistelli A & 6 & 8 & Harris KJ & 4 \\
\hline 4 & Lin CP & 6 & 9 & Cunningham GB & 4 \\
\hline 5 & Knudsen HK & 5 & 10 & Lee YH & 4 \\
\hline
\end{tabular}

\section{Research hotspot analysis}

For a paper, the keywords can generally reflect its research content, which is a concise summary of the paper. Therefore, the analysis of keywords can effectively reflect the research hotspots in the research field, and can summarize the research into different research topics based on keyword clustering. In this study, Citespace.5.5 clustered the keywords and finally obtained 7 important topics, as shown in Fig.2, and listed the high-frequency keywords in Table III.

\subsection{High frequency keywords}

Through the analysis of keywords, it is found that the keyword that appears most frequently in research related to turnover intention is turnover intention, the frequency reaches 485 times, intermediary centrality is 0.21 , followed by job satisfaction (frequency reaches 430 times), organizational commitment (Frequency reached 324 times), performance (frequency reached 227 times), employee turnover (frequency reached 173 times). The remaining high-frequency keywords in the top 20 are shown in Table III. These keywords reflect the research hotspot of turnover intention.

\section{\#5 moral dirtiness}

\section{\#3 psychological contract}

\#2 perceived organizational support

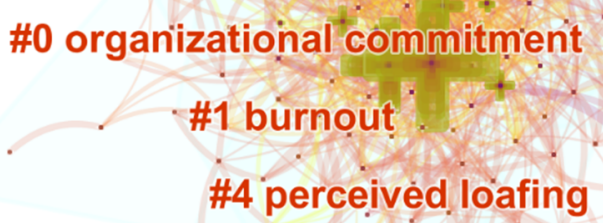

\section{\#6 turnover intention}

Figure 2. Turnover intention Keyword clustering map

TABLE III. Turnover intention high frequency keywords

\begin{tabular}{|c|l|c|c|}
\hline Num & \multicolumn{1}{|c|}{ Keyword } & Centrality & Freq \\
\hline 1 & turnover intention & 0.21 & 485 \\
\hline 2 & job satisfaction & 0.08 & 430 \\
\hline 3 & organizational commitment & 0.11 & 324 \\
\hline 4 & performance & 0.14 & 227 \\
\hline 5 & employee turnover & 0.11 & 173 \\
\hline 6 & model & 0.08 & 172 \\
\hline 7 & work & 0.04 & 164 \\
\hline 8 & antecedent & 0.03 & 155 \\
\hline 9 & Meta-analysis & 0.05 & 141 \\
\hline 10 & burnout & 0.11 & 135 \\
\hline 11 & impact & 0.02 & 115 \\
\hline 12 & stress & 0.06 & 85 \\
\hline 13 & perception & 0.05 & 85 \\
\hline 14 & consequence & 0.06 & 83 \\
\hline 15 & turnover & 0.04 & 76 \\
\hline 16 & behavior & 0.14 & 67 \\
\hline 17 & perceived organizational support & 0.03 & 67 \\
\hline 18 & attitude & 0.14 & 60 \\
\hline 19 & voluntary turnover & 0.04 & 58 \\
\hline 20 & leave & 0.02 & 55 \\
\hline
\end{tabular}

\subsection{Theoretical basis}

Through the mining of high-frequency keyword literature, it is found that the widely cited literature is Jensen [1], which discusses the relationship between highperformance work systems, job control, employee anxiety, role overload and turnover intention, which points out the "dark side" of turnover intention, the results suggest that high-performance work systems may have a negative impact on employees, which in turn affects the 
organization. The second is Griffeth [2], This study systematically summarizes the predictive factors of turnover, which is of great significance to the research related to turnover intention. Holtom's research makes a critical summary of the past employees' voluntary resignation related results, which has reference significance for guiding the subsequent research [3].

\subsection{Related Research on Turnover Intention}

Combining the keyword clustering and high-frequency keywords in Fig.2, the relevant research on turnover intention can be summarized into three categories. (1) Predictive factors of turnover intention, including job satisfaction, organizational commitment, burnout, stress, perceived organizational support, these factors are closely related to turnover intention. (2) Possible consequences of turnover intention. Turnover intentions have a significant predictive effect on employee turnover, especially employee voluntary turnover. In addition, turnover intention also has a certain impact on employee performance. (3) In terms of research methods, the current researches on turnover intentions mainly use meta-analysis methods. Because some scholars who study turnover intentions are from a psychological perspective, this research method has been widely used.

\section{Evolutionary trends}

Emergent words are keywords that increase suddenly over a period of time. Emergent words detection can analyze the research context of a research field and examine the changes in the subject of turnover intention research at different periods. Therefore, in this study, Citesapce.5.5 was used to detect emergent words with keywords as nodes, and 25 emergent words were obtained, as shown in Fig.3.

\begin{tabular}{|c|c|c|c|c|c|}
\hline Keywords & Year & rength & Begin & End & $2000-2019$ \\
\hline antecedent & 2000 & 6.9193 & 2000 & 2006 & \\
\hline organizational commitment & 2000 & 4.6642 & 2000 & 2008 & \\
\hline nodel & 2000 & 5.2052 & 2001 & 2005 & \\
\hline ontinuance & 2000 & 4.259 & 2004 & 2010 & \\
\hline ormative commitment & 2000 & 5.5982 & 2005 & 2013 & - \\
\hline Leterminant & 2000 & 5.2386 & 2007 & 2014 & \\
\hline onflict & 2000 & 4.669 & 2007 & 2009 & \\
\hline osychological contract & 2000 & 3.6429 & 2010 & 2013 & \\
\hline leader member exchange & 2000 & 3.9738 & 2010 & 2014 & \\
\hline ob stress & 2000 & 4.1031 & 2011 & 2013 & \\
\hline social exchange & 2000 & 3.4334 & 2011 & 2013 & \\
\hline job performance & 2000 & 6.1521 & 2012 & 2015 & \\
\hline job & 2000 & 3.5208 & 2012 & 2015 & \\
\hline role conflict & 2000 & 3.1174 & 2014 & 2015 & \\
\hline supervisor support & 2000 & 4.3368 & 2014 & 2015 & \\
\hline work-family conflict & 2000 & 3.2919 & 2014 & 2015 & \\
\hline job embeddedness & 2000 & 5.9524 & 2014 & 2017 & - \\
\hline service & 2000 & 3.6395 & 2014 & 2015 & ב_ \\
\hline leader-member exchange & 2000 & 3.1185 & 2014 & 2015 & $=---$ \\
\hline personality & 2000 & 3.796 & 2015 & 2017 & $=$ \\
\hline transformational leadership & 2000 & 4.3601 & 2016 & 2019 & - \\
\hline conservation & 2000 & 4.908 & 2016 & 2019 & \\
\hline identification & 2000 & 3.8128 & 2016 & 2019 & 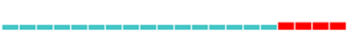 \\
\hline resource & 2000 & 6.7217 & 2016 & 2019 & - \\
\hline noderating role & 2000 & 4.4605 & 2016 & 2017 & \\
\hline
\end{tabular}

Figure 3. Turnover intention burst term map

In the first stage, from 2000 to 2013, keywords such as antecedent, organizational commitment, model, continuance, normative commitment, conflict, psychological contract, job stress, social exchange and other keywords emerged. This stage is the preliminary exploration of turnover intention, there is relatively little literature, and scholars mainly focus on the impact of organizational factors on turnover intentions. In the second stage, from 2014 to 2019, keywords such as job performance, leader member exchange, supervisor support, transformational leadership, job embeddedness, maintenance, identification, personality and other keywords emerged, that the literature related to turnover intention increased rapidly during this stage, scholars began to pay attention to the impact of turnover intentions. The prediction factors of turnover intention mainly focused on the influence of leadership style on turnover intention. For example, Alhashmi[4] explored the relationship between the exchange quality of leadership members and turnover intentions. The quality of leadership exchanges has a direct negative impact on turnover intentions; Yang Juan[5] studied the relationship between entrepreneurial leadership and employee turnover intention. The results show that entrepreneurial leadership can reduce employee turnover intentions, and this effect is achieved through the intermediary effect of the three factors of job embeddability, job satisfaction and emotional commitment. In addition, individual employee factors such as personality factors have also attracted scholars' attention.

\section{Conclusion And Suggestion}

Employee turnover has always been a headache for managers. Voluntary turnover has brought great potential danger to the organization. Therefore, scholars have conducted a lot of research on turnover intention that the important predictors of turnover behavior. This study is based on the knowledge graph theory and uses the knowledge of turnover intention on the Web of Science core collection to draw a knowledge graph for analysis. By analyzing the basic situation of scholars in the field of turnover intention through authors' cooperation network, identifying the research hotspots of turnover intention through high-frequency keywords and emergent words, clarifying the evolution of turnover intention, and drawing the following conclusions:

At first, from the perspective of the author's cooperation network, there are many scholars in the field of turnover intention research, but they are more scattered, and there is no larger research circle with close cooperation. Therefore, in the future, researchers should continue to expand the cooperation network of scholars, strengthen the exchange of disciplines and research topics, and integrate platform resources to further enhance the scale and influence of disciplines.

Secondly, from the perspective of the research topic, the research related to turnover intention mainly focuses on three aspects: influencing factors, consequences and research methods. At present, relevant research mainly focuses on the impact of organizational level, including working environment, leadership style, and other factors, on turnover intentions, and there is little exploration on the 
personal level and external factors. Therefore, in the future, researchers should expand the influence of employee's individual factors on turnover intentions, continue to explore the mechanism between the prediction factors of turnover intentions and turnover intention, and enrich the relevant theories of turnover intention.

Finally, from the perspective of evolutionary trends, research related to turnover intention has transitioned from the initial development stage to the rapid development stage. The initial development stage mainly focuses on the organizational factors of turnover intention, while in the rapid development stage, scholars begin to study the internal mechanisms of various factors and turnover tendency, and explore the boundary conditions of their effects. However, there are few studies on influencing factors outside the organization of turnover intention. Therefore, in the future, researchers should expand the influence of social factors on employee turnover intention, and examine employee turnover intention from more aspects.

This study has identified the research hotspots and evolutionary trends of turnover intention through quantitative analysis of literature related to turnover intention, which is conducive to scholars to have a systematic understanding of turnover intentions and also provides direction for future related research.

\section{References}

1. Jensen J M, Patel P C, Messersmith J G. Highperformance work systems and job control: consequences for anxiety, role overload, and turnover intentions[J]. Journal of Management, 2013, 39(6):1699-1724.

2. Griffeth R W, Hom P W, Gaertner S. A meta-analysis of antecedents and correlates of employee turnover: update, moderator tests, and research implications for the next millennium[J]. Journal of Management, 2000, 26(3):463-488.

3. Holtom B C, Mitchell T R, Lee T W, Eberly $M B$.Turnover and retention research: a glance at the past, a closer review of the present, and a venture into the future[J]. Academy of Management Annals, 2008, 2(1):231-274.

4. Alhashmi M, Jabeen F, Papastathopoulos A. Impact of leader-member exchange and perceived organizational support on turnover intention: The mediating effects of psychological stress[J]. Policing, 2019, 42(4):520-536.

5. Yang J, Pu B, Guan Z. Entrepreneurial leadership and turnover intention in startups: mediating roles of employees' job embeddedness, job satisfaction and affective commitment[J]. Sustainability, 2019, 11. 